\title{
Out-Of-Pocket Health Expenditure Among the Elderly in Kenya
}

\author{
Emmanuel Mulaa Opondo ${ }^{1} \&$ Martine Odhiambo Oleche ${ }^{1}$ \\ ${ }^{1}$ School of Economics, University of Nairobi, Nairobi, Kenya \\ Correspondence: Emmanuel Mulaa Opondo, School of Economics, University of Nairobi, P.O Box 30197-00100, \\ GPO, Nairobi, Kenya. Tel: 318262 Ext. 28122. E-mail: emaopo@gmail.com
}

Received: July 7, 2020 Accepted: August 14, 2020 Online Published: September 9, 2020

doi:10.5539/gjhs.v12n11p53

URL: https://doi.org/10.5539/gjhs.v12n11p53

\begin{abstract}
Financial risk protection against the burden of out-of-pocket health expenditure (OOPHE) by achieving universal health coverage (UHC) is a key health priority for developing countries. The elderly is a vulnerable demographic group that need this protection. This study sought to analyze how selected social and demographic factors affect OOPHE among the elderly in Kenya. Further, it aimed to determine the distribution of OOPHE among the various wealth quintiles in the elderly using a cross-sectional study. Data was sourced from the Kenya Household Health Expenditure and Utilization Survey (KHHEUS) 2013. The sample size $(2,853)$ consisted of individuals $\geq 60$ years who had utilized health services. A multiple regression model and concentration curves were applied. Increasing age, having chronic illnesses, male gender, higher education level, more wealth, possessing health insurance, increased distance, and a higher number of visits to the health facility positively affected OOPHE. These results were statistically significant $(P<.050)$ for presence of chronic illnesses, increasing age, possessing a health insurance cover and being in the richest wealth quintile and insignificant for the rest. Moreover, concentration curves revealed that out-of-pocket (OOP) health payments were concentrated in the richest quintile individuals. Consequently, OOPHE is a regressive way of funding health care among the elderly. In conclusion, elderly persons need financial protection when seeking health care: achievable mainly through health reforms, especially the ones targeting health insurance.
\end{abstract}

Keywords: Kenya, out-of-pocket health expenditure, the elderly, universal health coverage

\section{Introduction}

Age may be defined based on three perspectives, elapsed years or chronology; changing social role such as loss of productivity (through retirement), having adult children and finally a change in capability perceived by invalid or senile status; and changing physical characteristics (World Health Organization [WHO], 2002). Considering these, a person aged 60 years and above may consequently be considered as elderly. With incidence levels of poverty as high as 39.9 percent in Kenya, and considering the above three perspectives, an elderly person is a vulnerable person (United Nations Development Program [UNDP], 2017; WHO, 2002).

Life expectancy world-wide is expected to hit 81 years at the end of the twenty-first century from 46 years in 1950 . Furthermore, the number of people who are over 60 years will increase from the current 700 million to at least 2 billion by 2050 (The World Bank, 2010). This will likely result in a change in the global demographic composition as the elderly population rises (Channon et al., 2012; The World Bank, 2010). As a result, these dramatic changes in population will necessitate proper planning to guarantee better population health outcomes.

Kenya's population is projected to hit 85 million people by 2050: fertility rate will drop from an average of 8.1 children in 1978 to 2.4 children by 2050, while life expectancy will rise to 68 years (The World Bank, 2010). Whereas the average number of children being born will keep dropping, more people will live longer than in the past.

There is evidence to suggest effort towards welfare protection for the elderly in Kenya. The Older Persons Cash Transfer Program, started in 2007, gives a monthly stipend of $\$ 20$ to those over 65 years whose poverty levels are considered dire. Another program is the Health Insurance Subsidy Program (HISP) that targets the poorest and vulnerable - mostly the elderly - and provides them with health insurance coverage to enable them access health services (The World Bank, 2014).

Out-of-Pocket Health Expenditure (OOPHE) is the money from their budget that a household uses to pay for health care at the point of utilizing these services (Xu et al.,2006). According to Xu et al. (2006), the proportional 
composition of OOPHE in Kenya is medicines (69 percent), patient registration (13 percent), diagnosis (6 percent), consultation fees (5 percent) and others (7 percent).

Universal Health Coverage (UHC) ensures everyone uses promotive, preventive, curative, rehabilitative and palliative health services, of sufficient quality to be effective, while ensuring that the use of these services does not expose the user to financial hardship (WHO, 2010). Whereas Kenya seeks to achieve UHC as a priority agendum (2017-2022) (UNDP, 2017), OOPHE poses a major bottleneck to this plan. OOPHE hinders efforts to achieving equity in health care financing because it limits health access to only those with the ability to pay (WHO, 2010). When taken as a proportion of the household expenditure, OOP payments may be considered catastrophic health expenditures if they exceed a certain predetermined proportion such as 10 percent of the non-food household expenditure or 40 percent of the total household expenditure (Chuma \& Maina, 2012; Xu et al.,2006). In fact, these payments are an opportunity cost for other forgone needs that the household may have chosen to spend their resources on (Chuma \& Maina, 2012).

In Kenya, OOPHE is a persistent health system challenge. Total health expenditure (THE) relative to total government expenditure fluctuates at about 5 percent, government spending on health being half of the THE and the other half being private health expenditure (WHO, 2009b). This private health expenditure is composed mainly of OOP health payments that therefore limit access to health care.

Government spending on health reduces inequities in health access thus makes a country's health system more robust: inability of government funding health services usually means the people must pay - as OOPHE - to access such services (WHO, 2010). In Africa, for every $\$ 100$ of government money, $\$ 16$ goes to health, only $\$ 10$ is spent and only $\$ 4$ or less will go to the right health service (WHO, 2009a). Thus, the effective government spending on health will be less than stated or allocated, which is usually lower than recommended. Therefore, technical and allocative inefficiencies are major health system problems in Africa. The result is health systems that are reliant on OOPHE.

Worldwide, annually, about 150 million people suffer financial catastrophe by paying for health services OOP while about 100 million are pushed below the poverty line (Xu et al., 2007). The proportion of OOPHE to the total health expenditure globally is estimated to be at 40 percent: in some regions, notably the developing countries in Africa and Asia, this figure is as high as 60 to 70 percent while in the developed countries it ranges between 15 to 25 percent (Sanwald \& Theurl, 2014; WHO, 2010).

In Kenya, data from the National Health Accounts show that the proportion of OOPHE to THE was 54 percent in 2001/2, then 39.3 percent in 2005/6 and 40 percent in 2012/13. According to the Kenya National Bureau of Statistics (KNBS), the enrolment to mandatory health insurance is a paltry 6.8 million Kenyans; about 14 percent population proportion (KNBS, 2019). It further suggests that just about 20 percent of Kenyans have any form of health insurance meaning a vast majority of Kenyans rely on OOPHE when seeking healthcare.

Research on OOPHE in Kenya is scanty. It has already been demonstrated that Kenyan households spend at least 10 percent of their income on health and that the catastrophic health expenditure is borne mostly by the poor (Buigut et al., 2012; Chuma \& Maina, 2012). Furthermore, about 1.48 million Kenyans have been pushed below the national poverty line due to OOPHE (Chuma \& Maina, 2012). This paper narrows down the focus to the elderly demographic.

In seeking to understand OOPHE in the elderly, this study had two objectives. First to determine how selected social and demographic factors affect OOPHE in the elderly in Kenya. Second, to determine the distribution of these OOPHE in the different wealth quintiles.

\section{Methods}

\subsection{Data and Sampling}

This was a cross-sectional study. The data was sourced from the Kenya Household Health Expenditure and Utilization Survey (KHHEUS) 2013.KHHEUS is conducted periodically as part of the National Health Accounts. This was the third, and latest, of such surveys following the ones done in 2003 and 2007, respectively.

KHHUES 2013 provided national and county level data on OOP health payments, health seeking behavior, utilization of health services and health insurance coverage among Kenyans. The sampling for KHHEUS 2013 was based on the National Sample Survey Evaluation Programme (NASSEP) master sample that was developed by multistage sampling design. The sample size for this study were individuals who utilized health services and their age $\geq 60$ years (considered elderly).

From the dataset, 36,120 persons were ill while 35,883 utilized healthcare services and 2,853 were $\geq 60$ years (n). 


\subsection{Econometric Model}

The analysis of the various determinants of OOPHE in the elderly in Kenya was conceptualized along the multiple linear regression model as illustrated in Equation 1 below.

$$
\begin{aligned}
\operatorname{lnOOPHE}=a_{1} s & +a_{2} \ln \text { age }+a_{3} \text { sex }+a_{4} \text { education }+a_{5} \text { wealthindex }+a_{6} \text { insureancecov }+a_{7} \ln \text { distance } \\
& +a_{8} \ln v i s i t s+\varepsilon_{i}
\end{aligned}
$$

The variables in equation 1 were defined as follows.

lnOOPHE - is the natural logarithm of out of pocket expenditure (in Kenya shillings)

$s$ - is the presence of a disease in a household / individual

lnage - is the natural logarithm of the age (in years) of the respondent

sex - is the gender of the respondent

education - is the highest education level of the respondent

wealthindex - is the wealth index of the household

insurance cov - is the health insurance coverage status of the individual / household

Indistance - is the natural logarithm of the distance to the nearest health facility

lnvisits - is the natural logarithm of the number of visits to the health facility by the individual.

From the Andersen Model of Healthcare Utilization,1973, healthcare utilization can be viewed based on societal, health system and individual determinants (Andersen \& Newman, 1973). Some of these determinants formed the dependent variables of this study as in Equation 1. From the Grossman Model, individuals seek to enjoy health as a consumption and investment good by increasing their stocks of health (Grossman, 1972). Inputs that may increase stocks of health according to The Grossman Model and were considered in the study included education level, income level and medical services sought.

To study the distribution of OOPHE in the different wealth categories, concentration curves were plotted. On the $y$-axis was the cumulative percent of OOPHE, the health variable, while on the $x$-axis was the cumulative percent of the sample population ranked by amount of wealth.

\subsection{Data Diagnostics and Analysis.}

The correlation matrix was used to check the linear relationship between the variables (Supplementary Table S2). Then endogeneity was ruled out: achieved using the two-stage least square regression followed by the endogeneity test (Supplementary Table S4). Upon establishing absence of endogeneity, a multivariate regression based on Ordinary Least Square (OLS) was estimated. Breusch-Pagan / Cook-Weisberg test for heteroscedasticity indicated presence of heteroscedasticity (Supplementary Table S5); the regression model was then re-estimated using heteroscedasticity-free robust standard errors (Supplementary Table S6). These results were compared with those obtained earlier, before correcting for heteroscedasticity. The mean variance inflation factor was 1.94 (Supplementary Table S3) thus indicating absence of multi-collinearity.

\section{Results}

\subsection{Summary Statistics}

Tables 1 and 2 show the summary statistics of the data. The sample size was 2,853 individuals, a comprehensive summary of the dataset is displayed in Supplementary Table S1. More meaning could be deduced from the continuous and the multi-level categorical variables. Table 1 reveals the average age of those sampled as 64.5 years; the least age being 60 years and maximum age 81 years. Moreover, the average number of visits by the elderly to the hospital was about 2 visits per person after travelling an average distance of 5.49 kilometers to get to the health facility. The average OOPHE for an elderly person was Kenya shillings (KES) 921 (about \$9). The highest spent amount was KES 150,000 (about \$1,500).

From Table 2, the sample was composed of a majority middle quintile individual then poor, rich, poorest and richest had the least proportion. Also, the majority had primary level education followed by secondary education, higher education, and finally lower education. Whereas wealth and education were multi-level categorical variables, sex, chronic illnesses, and insurance coverage were only single level. 
Table 1 . Summary statistics of the continuous variables

\begin{tabular}{llllll}
\hline Variable name & Sample size(n) & Mean & Std. Dev. & Min & Max \\
\hline Visits & 2,853 & 1.5787 & 1.1374 & 1 & 12 \\
lnvisits & 2,853 & 0.4566 & 01287 & 0.0000 & 2.4849 \\
Age (years) & 2,853 & 64.5378 & 2.4356 & 60 & 81 \\
lnage & 2,853 & 4.1673 & 0.8902 & 4.0943 & 4.3944 \\
Distance $(\mathrm{km})$ & 2,853 & 5.4910 & 3.6028 & 0 & 50 \\
Indistance & 2,853 & 1.7031 & 1.2817 & - & 3.9120 \\
OOPHE(KES) & 2,853 & 921.157 & 6296.407 & 0 & 150,000 \\
lnOOPHE & 2,853 & 6.8256 & 8.7477 & - & 11.9184 \\
\hline
\end{tabular}

Note. KES indicates Kenya shillings; km, kilometers; ln, the natural logarithm; Max, the maximum value of the variable; Min, minimum value of the variable; Std. Dev., Standard deviation.

Table 2. Summary statistics of the categorical variables

\begin{tabular}{lllll}
\hline Variable name & Frequency & Proportion & Min & Max \\
\hline Wealth indices & $\mathbf{2 , 8 5 3}$ & & & 1 \\
poorest & 604 & 0.2117 & 0 & 1 \\
Poor & 685 & 0.2401 & 0 & 1 \\
middle & 765 & 0.2681 & 0 & 1 \\
Rich & 653 & 0.2289 & 0 & 1 \\
richest & 146 & 0.0512 & 0 & 1 \\
Education level & $\mathbf{2 , 8 5 3}$ & & & 1 \\
Lower education & 54 & 0.0189 & 0 & 1 \\
Primary education & 2525 & 0.8850 & 0 & 1 \\
Secondary education & 197 & 0.0691 & 0 & 1 \\
Higher education & 77 & 0.0270 & 0 & 1 \\
Insurance Coverage & 2,853 & 1.0000 & 0 & 1 \\
Chronic illnesses & 2,853 & 1.0000 & 0 & 0 \\
Sex & 2,853 & 1.0000 & 0 & 1 \\
\hline
\end{tabular}

Note. In indicates the natural logarithm; Max, the maximum value of the variable; Min, minimum value of the variable; Std. Dev., Standard deviation.

\subsection{Regression Results}

The multiple linear regression model was conducted after establishing that there was no endogeneity problem in the survey data used. The results of OLS multivariate regression, as displayed in Table 3 , revealed similarity to those of the multivariate regression based on the heteroscedasticity-free robust standard errors as shown in Supplementary Table S6. This was based on the conclusions drawn from the effect of the explanatory variables on OOPHE.

Table 3 indicates that the presence of chronic illness was likely to increase the household's OOPHE by 41.72 percent holding other factors constant. The estimated $t$-statistic was 3.51, and thus greater than the $t$-critical of 2 at 5 percent significance level meaning that this effect is statistically significant. This was further confirmed by the $P$ $=0.000$ which was less than the significance of 0.05 .

A similar effect was reported for the variable age of the individual. An extra year lived, among the elderly demographic in Kenya, increased the OOPHE incurred by almost three times holding the other variables constant. From Table 3, the estimated $t$-statistic 5.34 was greater than the $t$-critical of 2 at 5 percent significance level 
meaning this effect was statistically significant. Furthermore, the $P=0.000$ obtained was less than the level of significance of 0.05 . This implies that as an individual's number of years lived rises, the OOPHE was likely to increase significantly.

Further results indicated that individuals with health insurance cover were 36.58 percent more likely to have higher OOPHE than those individuals without health insurance. Table 3 shows that the estimated $t$-statistic of 2.01 obtained was greater than the value of $t$-critical of 2 at 5 percent significance level; $P=0.045$ and therefore less than the significance of 0.05 . These showed results for health insurance coverage were significant.

The distance covered by the patient was reported to have a positive effect on the OOPHE. An extra kilometer to the health facility increased the probability of OOPHE by 38.57 percent. However, the effect was found to be insignificant. This is because the estimated $t$-statistic was 1.63 at 5 percent significance level, therefore less than the $t$-critical of 2 as shown in Table 3. Furthermore, the $P=0.104$, was greater than the significance level of 0.05 .

The number of visits to the health facility reported a positive effect on OOPHE. One more visit increased the probability of OOPHE by 2.49 percent. The estimated $t$-statistic was 0.21 , thus less than the $t$-critical of 2 at 5 percent significance level as shown in Table 3. Also, the $P=0.836$ was greater than the significance level of 0.05 . This highlights the fact that the effect of the number of visits on OOPHE was statistically insignificant.

Regarding the gender, male patients were found to be more likely to spend more on OOPHE compared to their female counterparts by 17.68 percent. From Table 3 the estimated $t$-statistic was 1.42 , which was lower than the $t$-critical of 2 at 5 percent significance level therefore these results were statistically insignificant. This was confirmed by the $P=0.157$, which was greater than the significance level of 0.05 .

On the education level of the individual, an increasing level of education was found to have a positive effect on the OOPHE compared to the possession of lower education level only. Lower education, which was the reference group, was composed of individuals who had attended nursery school only or madrassas (educational institutions that teach Islamic studies to children). Individuals with primary, secondary and higher education levels were more likely to experience higher OOPHE than those with lower education by 36.35 percent, 65.11 percent and 32.06 percent respectively as depicted in Table 3 .

Table 3 also shows that the estimated $t$-statistic values for primary, secondary, and higher education were $0.86,1.37$ and 0.57 respectively and they were all less than the $t$-critical values of 2 at 5 percent significance level. Furthermore, their $P$-values were $0.388,0.170$ and 0.566 respectively and were all greater than the significance of 0.05 . This shows the effect of education level on OOPHE was statistically insignificant.

Regarding the wealth index of the households, results indicated that the poor and middle-income individuals were less likely to bear a high OOPHE compared to the poorest individuals. From Table 3 the poor were 15.18 percent less likely than the poorest to face OOPHE; the middle quintile individuals on the other hand were 13.64 percent less likely than the poorest. However, results indicated that rich and richest quintile individuals were more likely to incur more OOPHE compared to the poorest. The rich were 13.58 percent more likely to experience OOPHE than the poorest whereas the richest were 88.50 percent more likely than the poorest.

Furthermore, the estimated $t$-statistic values for the poor, middle and rich quintile individuals were $0.89,0.81$ and 0.76 respectively and they were all less than the $t$-critical statistic of 2 at 5 percent significance level. Their respective $P$-values were found as $0.374,0.418$ and 0.447 . This implies belonging to these wealth quintiles had a statistically insignificant effect on OOPHE.

On the other hand, considering the individuals in the richest quintile; the estimated $t$-statistic was 2.96 indicating the results were statistically significant. It was further confirmed by $P=0.003$ which was less than the significance level of 0.05 . 
Table 3. Results of the multivariate regression

\begin{tabular}{lllll}
\hline Variable & Coefficient & Std. Err. & $\boldsymbol{t}$-statistic & $\boldsymbol{P}$-value \\
\hline Chronic Illness & 0.4172 & 0.1188 & 3.51 & .000 \\
lnage & 2.9587 & 0.5537 & 5.34 & .000 \\
Male & 0.1768 & 0.1247 & 1.42 & .157 \\
Primary education & 0.3635 & 0.4206 & 0.86 & .388 \\
Secondary education & 0.6511 & 0.4745 & 1.37 & .170 \\
Higher education & 0.3206 & 0.5587 & 0.57 & .566 \\
Poor & -0.1518 & 0.1706 & -0.89 & .374 \\
Middle & -0.1364 & 0.1683 & -0.81 & .418 \\
Rich & 0.1358 & 0.1785 & 0.76 & .447 \\
Richest & 0.8850 & 0.2990 & 2.96 & .003 \\
Insurance coverage & 0.3658 & 0.1824 & 2.01 & .045 \\
lndistance & 0.3857 & 0.2369 & 1.63 & .104 \\
lnvisits & 0.0249 & 0.1207 & 0.21 & .836 \\
Constant & -11.97262 & 2.4278 & -4.93 & .000 \\
\hline
\end{tabular}

Note. In indicates natural logarithm; Std. Err., standard error.

\subsection{Concentration index results}

Figure 1 shows that all curves lay below the line of equality (45-degree line). The health variable of interest, OOPHE, therefore was concentrated among the rich. Moreover, figure 1 reveals that middle wealth individuals had the most dominant concentration curve. This implies that there was least inequality or OOPHE in this category of individuals compared to the other four.They were followed by the poorest, poor, rich and richest respectively.

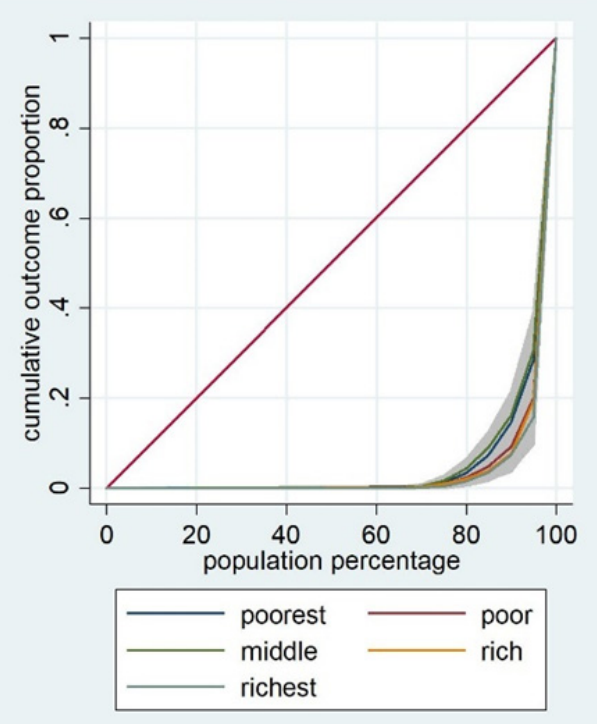

Figure 1. Concentration curves for the various wealth quintiles

\section{Discussion and Conclusion}

From the results, the presence of chronic illnesses significantly increased OOPHE. Chronic diseases are a proxy variable for deteriorating health status, which ultimately cause increased demand and utilization of health services (Brinda et al., 2014; Shen \& McFeeters, 2006). Increasing age also significantly increased OOPHE. It may be 
concluded that increasing age comes with diminishing physiological function and poor health status; this ultimately increases demand and utilization of health services as has also been evidenced by other studies (Brinda et al., 2014; Shen \& McFeeters, 2006).

Possessing health insurance significantly increased OOPHE. Being elderly exposes individuals to higher risk of utilizing more health services than if otherwise (Brinda et al., 2014; Shen \& McFeeters, 2006). By demanding more health services, elderly persons are more likely exposed to OOPHE than the non-elderly (Park et al., 2015). Furthermore, the health insurer consciously aware of the existing information asymmetry, choses to discourage the likely moral hazard by introducing copayments and policy limits which ultimately increase OOPHE (Shen \& McFeeters, 2006).

In Namibia and Liberia, possessing health insurance coverage reported similar results (Wang et al., 2016). It may therefore be concluded that the health insurance coverage provided is not comprehensive enough and only covers basic health services, leaving patients to pay OOP for most of the other spectrum of services. Most of those with health insurance had the basic mandatory health insurance (National Hospital Insurance Fund in Kenya), which has a narrow benefit package leaving most health services to be accessed by incurring OOPHE. The other conclusion was that the health insurance policy covers may have clauses, such as not covering 'pre-existing health conditions', which make the elderly spend more on OOPHE as they may already have these conditions manifesting as chronic illnesses (Park et al., 2015). Finally, the health insurance regulatory mechanisms weaknesses lead to high copayments fees, deductibles and long, winding claim procedures that work against the elderly and still make them prefer to pay OOP.

Health insurance, be it mandatory, private or social insurance, should work to bring down if not eliminate OOPHE. Kenya, and other developing nations, should undertake reforms in the health insurance sector to achieve this. Adopting economic evaluation, through health technology assessment (HTA) would guide in having cost-effective health insurance benefit packages and further assist in strategic purchasing of health services. This would in turn lead to both technical efficiency (sufficiency of health services) and allocative efficiency (the right services) for the elderly thus protect them from OOPHE (Dang et al., 2016).

The other factors were distance to the health facility, number of visits, education level and male sex; these similarly increased OOPHE. However, their effect was not significant. It may be concluded that elderly Kenyans travelled longer distances when they were likely to utilize more health services thus being exposed to higher OOPHE. This may be through medical referrals, emergency cases or otherwise, from a lower level health facility to a higher level one.

Similarly, a higher number of visits to the health facility translated to higher treatment costs that may manifest as higher OOPHE. More visits to the facility imply higher utilization of health services, which makes the health seeker susceptible to OOPHE. However, this is dependent on what proportion of health costs the elderly person bears during such visits. With a comprehensive health insurance cover, elderly persons can be financially protected against OOPHE that may impoverish them.

The results on wealth could be explained by the high prevalence of poverty levels. Kenya's incidence of poverty is 39.1 percent with 14.5 percent of the population living in utmost poverty (UNDP, 2017). The elderly, being a more dependent and less productive demographic, are afflicted more than the general population. This makes seeking health services a luxury that only those considered rich visit health facilities to seek health care. It may be concluded that it is this group that will ultimately incur OOPHE. The concentration curve results, as in Figure 1, show OOPHE being concentrated among the rich therefore further reinforcing this conclusion.

Individuals having higher education are better consumers of health education (Brinda et al., 2014). It is therefore probable that they are likely to be conscious of the importance of good health. They will partake of actions that increase their stocks of health better than those who are less educated (Grossman, 1972). Such actions include health promotive, preventive, curative and rehabilitative measures. Through these they will likely incur health costs and most likely OOPHE.

Male sex positively affected OOPHE. Research on this is varies, with a study from neighboring Tanzania showing that being of female sex increases OOPHE significantly (Brinda et al., 2014). Elsewhere in India, data showed marked gender disparities in health care expenditure for the elderly biased against women (Maharana \& Ladusigh, 2014). We may conclude this through two perspectives; in earlier years, men are likely to lead more riskier lives through overindulgence. This may manifest later in old age as chronic illnesses that may cause them to seek health care more than women. Second, most females in developing countries are poorer in comparison to men (Maharana \& Ladusigh, 2014). This limits their ability to seek health even when they need it. The outcome of this that men 
spend more, and women less, as OOPHE.

\section{Study limitation}

The data used, KHHEUS 2013, was more than six years old. While it is noteworthy that some variables may have since changed, no other health household survey of its kind has been done. Therefore, it remains the most recent data as at submission of this manuscript.

\section{Acknowledgements}

We acknowledge David Muriithi for his role in data analysis.

\section{Competing Interests Statement}

The authors declare that there are no competing or potential conflicts of interest.

\section{References}

Andersen, R., \& Newman, J. F. (1973). Societal and individual determinants of medical care utilization in the United States. The Milbank Memorial Fund Quarterly. Health and Society, 51(1), 95-124.

Buigut, S., Ettarh, R., \& Amendah, D. D. (2015). Catastrophic health expenditure and its determinants in Kenya slum communities. International Journal for Equity in Health, 14(46), 1-12. https://doi.org/10.1186/s12939-015-0168-9

Brinda, E. M., Andres, R. A., \& Enemark, U. (2014). Correlates of out-of-pocket and catastrophic health expenditure in Tanzania: Results from a national household survey. BMC International Health Human Rights, 14(5). https://doi.org/10.1186/1472-698X-14-5

Channon, A. A., Andrade, M. V., Noronha, K., Leone, T., \& Dilip, T. R. (2012). Inpatient care of the elderly in Brazil and India: Assessing social inequalities. Social Science \& Medicine, 75(12), 2394-2402. https://doi.org/10.1016/j.socscimed.2012.09.015

Chuma J., \& Maina, T. (2012). Catastrophic health care spending and impoverishment in Kenya. BMC Health Services Research, 12(413). https://doi.org/10.1186/1472-6963-12-413

Dang A., Likhar, N., \& Alok, U. (2016). Importance of economic evaluation in health care. An Indian perspective. Value in Health Reginal Issues, 9(C), 78-83. http://dx.doi.org/10.1016/j.vhri.2015.11.005

Grossman, M. (1972). On the concept of health capital and demand for health. Journal of Political Economy, 80(2), 223-255.

Kenya National Bureau of Statistics. (2019). Economic survey. Nairobi, Kenya: Kenya National Bureau of Statistics.

Maharana, B., \& Ladusigh, L. (2014). Gender disparity in health and food expenditures in India among the elderly. International Journal of Population Research. https://doi.org/10.1155/2014/150105

Park, E., Kwon, J., Lee, E., Jung, Y., \& Park, S. (2015). Out-of-pocket medication expenditure burden of elderly Koreans. International Journal of Gerontology, 9,166-171. http://dx.doi.org/10.1016/j.ijge.2014.06.005

Sanwald A., \& Theurl, E. (2014). What Drives Out-of-Pocket Health Expenditures for Private Households? Empirical Evidence from Austrian Household Budget Survey. Working Papers 2014-04, Faculty of Economics and Statistics, University of Innsbruck. Retrieved from https://ideas.repec.org/p/inn/wpaper/2014-04.html

Shen, Y., \& McFeeters, J. (2006). Out-of-pocket health spending between low-and higher-income populations: who is at risk of having high expenses and high burdens? Medical Care, 44(3), 200-209. https://doi.org/10.1097/01.mlr.0000199692.78295.7c

The World Bank. (2010). Demographic transition and growth in Kenya. Retrieved 3rd July, 2020, from https://www.worldbank.org/en/news/opinion/2010/04/28/demographic-transition-growth-kenya

The World Bank. (2014). Improving Health Care for the Poor. Retrieved $3^{\text {rd }}$ July 2020, from http://www.worldbank.org/en/news/feature/2014/10/28/improving-healthcare-for-kenyas-poor

United Nations Development Program. (2017). UNDP Kenya 2017 Annual Report. Nairobi, Kenya: United Nations Development Program.

Wang, W., Temsah, G., \& Carter, E. (2016). Levels and Determinants of Out-of-Pocket Health Expenditures in the Democratic Republic of the Congo, Liberia, Namibia and Rwanda. Rockville, Maryland, USA: International 
Health and Development, ICF International. Retrieved from https://dhsprogram.com/pubs/pdf/AS59/AS59.pdf

World Health Organization [WHO]. (2002). Health statistics and information systems. proposed working definition of an older person in Africa for the MDS project. Retrieved $3^{\text {rd }}$ July 2020, from http://www.who.int/healthinfo/survey/ageingdefnolder/en/

World Health Organization [WHO]. (2010). Health systems financing: the path to universal health coverage. World Health Report 2010. Geneva, Switzerland: World Health Organization. Retrieved from https://apps.who.int/iris/bitstream/handle/10665/44371/9789241564021_eng.pdf;jsessionid=D13A8747B91 42849D5F5BE2BD87C457F? sequence $=1$

World Health Organization [WHO]. (2009a). Public financing for health in Africa: from Abuja to the SDGs. Geneva, Switzerland: World Health Organization. Retrieved from https://apps.who.int/iris/rest/bitstreams/1060485/retrieve

World Health Organization [WHO]. (2009b). World Health Statistics 2009. Paris, France: World Health Organization. Retrieved from https://www.who.int/gho/publications/world_health_statistics/EN_WHS09_Full.pdf

Xu, K., Evans, D. B., Carrin, G., Aguilar-Rivera, A. M., Musgrove, P., \& Evans, T. (2007). Protecting households from catastrophic health spending. Health Affairs, 26(4), 972-983. https://doi.org/10.1377/hlthaff.26.4.972

Xu, K., James, C., Carrin, G., \& Muchiri, S. (2006). An empirical model to health care, health care expenditure and impoverishment in Kenya: Learning from the past reforms and lessons for the future. Nairobi, Kenya: World Health Organization. Retrieved from https://www.who.int/health_financing/documents/dp_e_06_3-access_kenya.pdf?ua=1

\section{Supplementary Tables Showing More Breakdown of the Data and Analysis of the Results}

Supplementary Table S1. Summary of the Database

\begin{tabular}{|c|c|c|c|}
\hline \multicolumn{4}{|c|}{ Those who were over 60 years and below 60 years } \\
\hline & Frequency & Percent & Cumulative \\
\hline$<60$ years & 145,036 & 95.06 & 95.06 \\
\hline$\geq 60$ years & 7,530 & 4.94 & 100.00 \\
\hline Total & 152,566 & 100.00 & \\
\hline \multicolumn{4}{|c|}{ Those who were ill and sought for healthcare } \\
\hline Yes & 35,883 & 99.34 & 99.34 \\
\hline No & 237 & 0.66 & 100.00 \\
\hline Total & 36,120 & 100.00 & \\
\hline \multicolumn{4}{|c|}{ Those who were ill, sought for healthcare and age $\geq 60$ years } \\
\hline Yes & 2,853 & 99.83 & 99.83 \\
\hline No & 5 & 0.17 & 100.00 \\
\hline Total & 2858 & 100.00 & \\
\hline
\end{tabular}

Note. The sample size (n) was taken as those who were ill, demanded health care and age $\geq 60$ years. Therefore $n=2,853$ for this study. 
Supplementary Table S2. Correlation Analysis Matrix

\begin{tabular}{|c|c|c|c|c|c|c|c|c|c|}
\hline & OOPHE & Insured & Distance & Visits & Wealth Index & Education & Sex & Age & Chronic Illness \\
\hline OOPHE & 1.0000 & & & & & & & & \\
\hline Insurance coverage & 0.1224 & 1.0000 & & & & & & & \\
\hline lndistance & 0.0418 & 0.0687 & 1.0000 & & & & & & \\
\hline lnvisits & 0.0005 & 0.052 & -0.0600 & 1.0000 & & & & & \\
\hline Wealth Index & 0.0886 & 0.253 & 0.0133 & 0.1089 & 1.0000 & & & & \\
\hline Education & 0.0259 & 0.1729 & 0.0354 & -0.0057 & 0.2201 & 1.0000 & & & \\
\hline Sex & -0.0179 & 0.0463 & 0.0438 & -0.1049 & -0.033 & 0.1389 & 1.0000 & & \\
\hline lnage & 0.0322 & -0.0384 & 0.0149 & -0.0512 & -0.0501 & -0.0893 & 0.0354 & 1.0000 & \\
\hline Chronic Illness & 0.0188 & 0.0623 & 0.06 & 0.1441 & 0.1487 & 0.0391 & -0.078 & 0.063 & 1.0000 \\
\hline
\end{tabular}

Note. No two variables exceeded the cut-off of 0.5. In indicates natural logarithm; OOPHE Out-of-pocket Health Expenditure.

Supplementary Table S3. Multicollinearity Test

\begin{tabular}{lll}
\hline Variable & VIF & $\mathbf{1 / V I F}$ \\
\hline Primary & 5.51 & 0.181493 \\
Secondary & 4.43 & 0.225732 \\
Higher education & 2.51 & 0.398686 \\
Rich & 1.72 & 0.581223 \\
Middle & 1.7 & 0.587738 \\
Poor & 1.63 & 0.614988 \\
Richest & 1.33 & 0.752813 \\
Insured & 1.13 & 0.888488 \\
Sex & 1.07 & 0.93082 \\
Chronic illness & 1.06 & 0.943427 \\
Logvisits & 1.05 & 0.950367 \\
Logage & 1.03 & 0.974188 \\
Logdistance & 1.02 & 0.978147 \\
Mean VIF & $\mathbf{1 . 9 4}$ & \\
\hline Note. VIF & 1.94 inich & \\
\hline
\end{tabular}

Note. VIF indicates Variance Inflation Factor. Mean VIF $=1.94$ which was below 10, the threshold above which multicollinearity would have been considered present. 
Supplementary Table S4. Two-Stage Least Square Regression results and endogeneity.

The Two-stage Least Square Regression was followed by the endogeneity test to give these results.

\begin{tabular}{lllllll}
\hline logOOPHE & Coefficient & Robust Std. Err. & $\mathrm{z}$ & $P>\mathrm{z}$ & {$[95 \%$ Conf. } & Interval] \\
\hline Sex & -4.6435 & 4.6946 & -0.99 & .323 & -13.84464 & 4.557734 \\
primary & 18.9587 & 34.9975 & 0.54 & .588 & -49.63511 & 87.55254 \\
secondary & 19.4778 & 42.0589 & 0.46 & .643 & -62.95609 & 101.9117 \\
Higher education & 23.9637 & 27.8425 & 0.86 & .389 & -30.60664 & 78.53399 \\
Chronic illness & 0.02152 & 0.3867 & 0.06 & .956 & -.7364452 & .7794906 \\
Lnage & 4.0918 & 1.6612 & 2.46 & .014 & .8359237 & 7.347677 \\
lnvisits & -0.5588 & 0.7004 & -0.80 & .425 & -1.931668 & .8140203 \\
Indistance & 0.5487 & 0.5848 & 0.94 & .348 & -.5975705 & 1.694906 \\
Insurance coverage & 0.2563 & 0.5607 & 0.46 & .648 & -.8426629 & 1.355195 \\
Constant & -33.4279 & 39.8648 & -0.84 & .402 & -111.5615 & 44.70571 \\
\hline
\end{tabular}

Instrumented: sex primary secondary higher education

Instruments: chronic illness logage logvisits logdistance insured poor middle rich richest

Test for endogeneity

Ho: variables are exogenous

Robust score chi2(4) $=10.3582(P=0.348)$

Robust regression $\mathrm{F}(4,2839)=2.69544(P=0.293)$

Note. In indicates natural logarithm; Std. Err. is the Standard Error; Conf. interval are the confidence intervals

$P=0.348$ thus $P$-value $>\alpha$, Wooldridge score does not reject the Ho that independent variables of the model are all exogenous at the 5 percent significance level used. Therefore, there was no endogeneity problem in the data.

Supplementary Table S5. Heteroscedasticity Test

Breusch-Pagan / Cook-Weisberg test for heteroscedasticity

Ho: Variance $\left(\mathrm{u} \mid \mathrm{x}_{1}, \mathrm{x}_{2} \ldots \mathrm{x}_{\mathrm{k}}\right)$ is constant

$\operatorname{chi} 2(1)=88.47 \quad$ Prob $>\operatorname{chi} 2=0.0000$

Note. Prob $>$ chi2 $=0.0000$. Therefore, the null hypothesis of constant variance is not accepted. Model was thus re-estimated using heteroscedasticity-free robust standard errors.

Table S6. Regression results based on the robust standard errors

\begin{tabular}{lllll}
\hline InOOPHE & Coefficient & $\begin{array}{l}\text { Robust } \\
\text { Std. Err. }\end{array}$ & $t$ & $P>\mathrm{t}$ \\
\hline Chronic Illness & 0.4172 & 0.1184 & 3.52 & .000 \\
lnage & 2.9587 & 0.5720 & 5.17 & .000 \\
Male & 0.1768 & 0.1256 & 1.41 & .159 \\
Primary & 0.3635 & 0.3647 & 1.00 & .319 \\
Secondary & 0.6511 & 0.4416 & 1.47 & .140 \\
Higher education & 0.3206 & 0.5760 & 0.56 & .578 \\
Poor & -0.1518 & 0.1598 & -0.95 & .342 \\
Middle & -0.1364 & 0.1618 & -0.84 & .399 \\
Rich & 0.1358 & 0.1800 & 0.75 & .450 \\
\hline
\end{tabular}




\begin{tabular}{lllll}
\hline Richest & 0.8850 & 0.3610 & 2.45 & .014 \\
Insured & 0.3658 & 0.2127 & 1.72 & .086 \\
Indistance & 0.3857 & 0.2916 & 1.32 & .186 \\
Invisits & 0.0249 & 0.1228 & 0.2 & .839 \\
Constant & -11.9726 & 2.5091 & -4.77 & .000 \\
\hline
\end{tabular}

Note. In indicates natural logarithm; OOPHE, Out-of-pocket health expenditure.

\section{Copyrights}

Copyright for this article is retained by the author(s), with first publication rights granted to the journal.

This is an open-access article distributed under the terms and conditions of the Creative Commons Attribution license (http://creativecommons.org/licenses/by/4.0/). 